\title{
Poesia em campo expandido: uma leitura de Sabonete Pôncio Pilatos, de Diego Dourado
}

\author{
Poetry in the Expanded Field: A Reading of Sabonete Pôncio Pilatos, by Diego Dourado \\ Poesía en campo expandido: una lectura de Jabón Poncio Pilatos, de Diego Dourado
}

Telma Scherer*

\section{Resumo}

Este artigo pretende articular uma leitura de um poema contemporâneo no qual estão presentes hibridismos, alargamentos de campo e diálogos entre linguagens. O trabalho escolhido é Sabonete Pôncio Pilatos, do poeta maranhense Diego Dourado, o qual pode ser pensado como poema-objeto, poema-performance, poesia conceitual, poema expandido, entre outras categorias provisórias e insuficientes. Situada no entrelugar entre poesia e artes plásticas, a obra agencia relações com o contexto de produção e circulação, convidando a uma leitura de seu caráter presencial e interartístico, que leva a questionarmos a relação entre as escolhas matéricas e suas reverberações políticas.

Palavras-chave: poesia expandida, Diego Dourado, materialidade, diálogos interartes.

\begin{abstract}
This article aims to read a contemporary poem that features dialogues between languages, expanding the poetical field. The chosen work, Sabonete Pôncio Pilatos, by the Brazilian poet Diego Dourado, can be thought of as an poem-object, a performance, conceptual poetry, or an expanded poem, among other temporary and insufficient categories. Located at the intersection between poetry and the visual arts, the work establishes relations between the context of its production and the modes of its circulation, inviting a reading of its face-to-face and inter-art character that calls on us to reflect on the relationship between the material choices in composition and the political reverberations of those choices.
\end{abstract}

Keywords: expanded poetry, Diego Dourado, materialities, inter-art works.

\begin{abstract}
Resumen
Este artículo presenta una lectura de un poema contemporáneo en el que están presentes hibridismos, ampliaciones de campo y diálogos entre lenguajes. El trabajo escogido es Jabón Poncio Pilatos, del poeta Diego Dourado, el cual puede ser pensado como poema-objeto, poema-performance, poesía conceptual, poema expandido, entre otras categorías provisionales e insuficientes. En el entrelazado entre poesía y artes plásticas, la obra agencia relaciones con el contexto de producción y circulación, invitando a una lectura de su carácter presencial e interartístico que lleva a cuestionar la relación entre las elecciones materiales y las reverberaciones políticas de las mismas.
\end{abstract}

Palabras-clave: poesía expandida, Diego Dourado, materialidad, diálogos interartes.

Herberto Helder, em Photomaton $\mathcal{E}$ Vox, dedicou algumas páginas a realizar uma leitura da poesia a partir da intermidialidade:

O corte das linhas (não as designemos por versos), as correspondências fonéticas, os ecos e mesmo as repetições vocabulares, equivalendo às disposições de volumes numa pintura, não são os sós motores do ritmo.

Nem o são apenas as distorções, inversões e deslocações da apresentação iconográfica; [...] Pense-se ainda que os substantivos não são palavras, mas objectos distribuídos;

\footnotetext{
" Universidade Federal de Santa Catarina (UFSC), Florianópolis, SC, Brasil. (Dorcid.org/0000-0003-0030-6360. E-mail: rumordacasa@gmail.com
} 
$[\ldots]$

Tudo isto instiga à percepção do ritmo. É um quadro.

$[\ldots]$

O cinema extrai da pintura a acção latente de deslocação, de percurso. Tome-se um poema: não há diferença. (Helder, 2017, p.141-142)

No mesmo texto, profetizou que os poetas do futuro criariam suas obras com câmeras nas mãos. Essa previsão de um futuro de materialidades expandidas para a criação poética está alicerçada, como se percebe desde o trecho acima, em certo entendimento da literatura que ultrapassa os limites da especificidade em termos de matéria e de linguagem: "Homero é cinematográfico, Dante é cinematográfico, Pound e Eliot são cinematográficos" (Helder, 2017, p. 139). O ritmo visual das imagens em movimento aparece no texto de Helder profundamente ligado ao ritmo cadenciado da poesia e da música. O ritmo está no quadro, no poema que dispõe seus substantivos do mesmo modo como um pintor dispõe suas formas no plano, e está no cinema.

Helder vai além, portanto, de uma percepção moderna das categorias poesia-tempo e imagem-espaço, alicerçada na antiga querela do Ut pictura poesis, ${ }^{1}$ iniciada com Simônides de Ceos, na antiguidade, pontuada com uma frase de Horácio (essa mesma que dá nome à polêmica: poesia é como pintura), retrabalhada nas comparações renascentistas entre as artes e ressurgida com toda a força no século XVIII. ${ }^{2}$

As relações entre imagem e palavra, entre música e poesia (artes do tempo) e pintura, escultura e arquitetura (artes do espaço) foram objeto de inúmeros debates e querelas, nas quais, muitas vezes, segundo o espírito da época, havia uma vontade de determinar qual delas era mais completa, mais importante ou mais frutífera. Inclui-se aí a afirmação da pintura como "cosa mentale" por Da Vinci e o entendimento oitocentista sobre a antiguidade, que retomou os valores da poesia, por Lessing. ${ }^{3}$

Percebemos, portanto, que o debate interartístico tem raízes profundas na tradição, antecedendo em muito as experimentações de vanguarda, que, a partir do final do século XIX, vêm afirmando procedimentos com base na dissolução das fronteiras intermídia. Poetas de muitas gerações vinham pensando o fazer poético em campos linguísticos alargados, expandidos, tanto no sentido das materialidades utilizadas na composição quanto no das ferramentas disponíveis para o entendimento da poesia.

De um modo muito específico, os poetas concretos firmaram essas relações no conceito de uma poesia verbivocovisual (Campos, Pignatari e Campos, 2006). O raio de ação do significante poético, segundo eles, contém camadas sonoras, visuais e de significado, todas concorrendo para a extrema "condensação" (Pound, s.d.), característica da função poética, jogando entre si, manifestando-se enquanto matéria de modelagem e de fruição. As pesquisas e criações dos concretistas forneceram os aportes mais conhecidos e vigorosos às práticas daqueles que trabalharam essas inflexões sonoras e visuais da poesia, no contexto da criação contemporânea brasileira.

Um deles é certamente o poeta Diego Dourado, autor de Sabonete Pôncio Pilatos, obra que é objeto deste artigo. Podemos citar outros nomes que, desde os anos 1990, vêm produzindo trabalhos que dialogam com esse legado: Ricardo Aleixo, Arnaldo Antunes, Marcello Sahea, Amarildo Anzolin, Wilmar Silva, Ricardo Corona, Reuben da Cunha Rocha/cavalodadá, Ronald Augusto, Omar Salomão, entre outros. É possível compreender essa produção sem estabelecer o ideário do "novo" ou recorrer a um entendimento de "vanguarda", circunscrito aos valores do contexto de surgimento da poesia concreta no Brasil, e às determinações da poesia calcada nas fórmulas e critérios modernos. Muitos desses poetas, inclusive, não se

\footnotetext{
${ }^{1}$ Para uma leitura de textos fundacionais sobre a querela, ver Lichtenstein (2006).

${ }^{2}$ Joana Matos Frias oferece uma discussão no artigo "Ut pictura poesis non erit" (Frias, 2008).

${ }^{3}$ Se, com Simônides, a pintura fora definida como "poesia muda", Leonardo inverteria a fórmula tratando a poesia como "pintura cega", conforme as suas afirmações no Tratado da Pintura (Da Vinci, 1943; Lessing, 2011).
} 
consideram continuadores do concretistmo. ${ }^{4}$ Os hibridismos praticados nas criações contemporâneas, mesmo aquelas nas quais há uma radicalidade no uso de materiais e procedimentos, não se pretendem inaugurais, ou subversivos. Absorveram das pesquisas anteriores muitas referências frutíferas, revitalizando-as, e propuseram seus próprios esquemas compositivos, que se alicerçam em práticas das várias linguagens da arte, sem se limitar a um ideário unívoco e a uma única busca.

O trânsito interartístico presente na produção de Diego Dourado, como de tantos outros poetas contemporâneos, gera trabalhos híbridos, nos quais a "tensão das palavras-coisas no espaço-tempo" (Campos, Pignatari e Campos, 2006) - a que os concretos se referiram em seu plano-piloto e em suas falas afora - reanima problemáticas e propõe questões que convidam a uma leitura dos mecanismos compositivos da poesia expandida, já liberada do desejo especifista e da avidez da vanguarda, pronta para saltar no meio da multidão e ativar uma rede de reverberações do sentido político da escolha de materiais e procedimentos.

Diego Dourado tem explorado essa tensão, inserindo no espaço-tempo o peso de suas palavras-coisas, em múltiplas manifestações: poemas visuais, poemas-performance, vocalidades, objetos. A consciência da implicação da escolha de meios e modos de manifestação da sua poesia, no sentido político, se relaciona a uma investigação matérica e formal que dissolve a falsa dualidade entre preocupações de linguagem/forma e posicionamento/atuação em relação às questões sociais.

Chama a atenção, na produção de Diego Dourado, a diversidade de materialidades empreendidas e a complexidade com que elas concorrem para uma fruição do resultado como texto global, formado por várias camadas significantes (verbivocovisuais). Em Nós (Dourado, 2015), ele propõe um poema que se manifesta no espaço-tempo de uma ação de grafar a palavra "nó" no chão, com pincel atômico, até compor uma mancha em formato de ovo, de linhas emaranhadas, poema-action-painting - segundo ele, também poema-processo (Dourado, 2016).

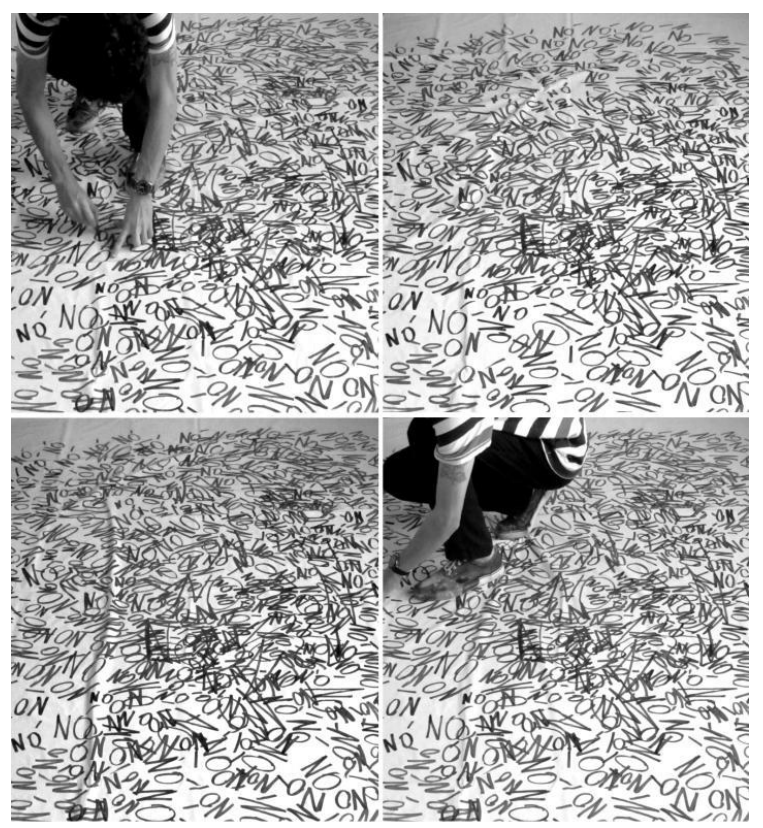

Figura 1 - Diego Dourado, Nós (o processo poético), 2015.

Fonte: Dourado (2016, p. 45).

\footnotetext{
${ }^{4}$ Nesse sentido, é interessante perceber a fala do poeta Ricardo Aleixo (2017, p. 39), quando comenta sua relação com a obra de Augusto de Campos: "Assumo a influência. Influência que - me permito inverter semanticamente - é também influir sobre. Eu me aproprio daqueles elementos da obra do Augusto que poderão me servir para o que eu quero dizer".
} 
O resultado dialoga com outros poemas-ovo da tradição, lançando a eles novas implicações, devido às escolhas processuais. A gestualidade, a presença física do autorexecutor, tem tanta importância para a estrutura do trabalho quanto as letras que formam a palavra "nó", repetida à exaustão. Aqui caberia pensarmos sobre performance nos termos em que Phillip Auslander (2012) fala sobre a "performatividade da documentação de performance", já que o poema não apenas reside no resultado obtido, na imagem escrita/inscrita no chão, e sim de modo mais produtivo, também na performance, à qual temos acesso por meio de fotos, que contêm a sua "performatividade".

O poema Nós foi escolhido para introduzir, de modo conciso, a problemática que irrompe dessa obra, mas cabe aqui apresentar um pouco melhor o poeta antes de entrarmos na leitura de Sabonete Pôncio Pilatos. Diego Dourado é um poeta maranhense, radicado em Porto Alegre, que tem atuação nos campos da poesia visual, apresentações ao vivo, livros, objetos, vídeos, realizando também intervenções urbanas e performances. Tem parcerias com Celso Borges, Reuben da Cunha Rocha/cavalodadá, Richard Serraria, entre outros. Performa em eventos ao vivo, participa de feiras e festivais pelo Brasil, instala poemas no espaço, vende seus trabalhos. Tem formação em Artes Visuais, com mestrado no Instituto de Artes da Universidade Federal do Rio Grande do Sul, sob orientação da artista e professora Elida Tessler. Publicou, pela 7 Letras, o livro Antologia de estilhaços (Dourado, 2015).

Entre suas referências, Diego cita o "Plano piloto da poesia concreta" como um ponto de partida, e também elenca proposições como as de Paulo Bruscky ou Dick Higgins, os quais, orbitando em paisagens próximas às da poesia concreta, não necessariamente partem dos mesmos pressupostos no sentido do contexto social, histórico e referencial. O trabalho de Diego, de modo geral, desliza entre rótulos e determinações de área, alimentando-se de entrelugares entre diversas linguagens das artes, tendo na palavra poética um foco centralizador.

Em Sabonete Pôncio Pilatos, de 2014, o poeta produz um sabonete, com todas as características de um sabonete fino de marcas tradicionais. O design da embalagem, realizado por Camila de Meneses, claramente se alicerça em referências que vêm desses produtos.

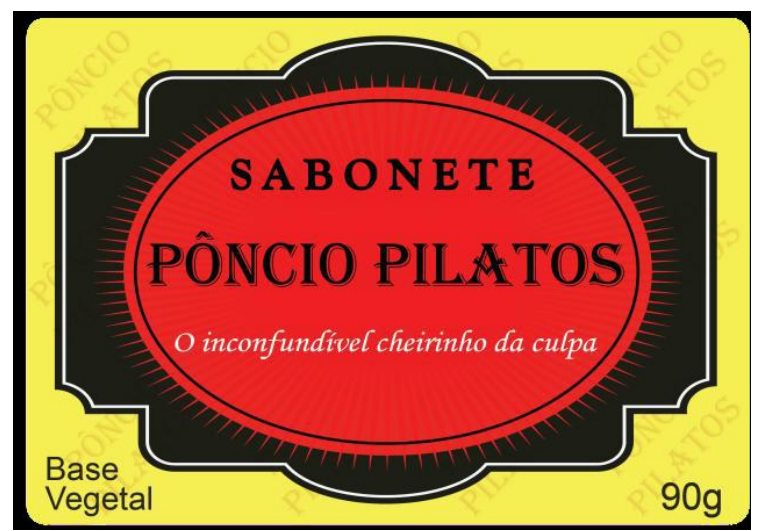

Figura 2 - Diego Dourado e Camila de Meneses, Sabonete Pôncio Pilatos, 2014.

Fonte: Dourado (2016, p. 137).

O sabonete é vendido nas ruas, junto de outros camelôs com seus produtos. Parcerias oportunizaram, além do design da embalagem, a criação de um vídeo-propaganda do sabonete. O próprio autor/artista realiza as vendas do produto e aparece no comercial, com seu tabuleiro, fornecendo os sabonetes para a população, que é entrevistada para opinar sobre a mercadoria. Há um agenciamento do social dentro do próprio poema-sabonete que nos interessa analisar em suas relações com o "campo expandido" no qual / do qual esse trabalho emerge.

A busca por "outras possibilidades de espacialização da palavra" é apontada por Dourado (2016) como horizonte dos desejos, em um breve comentário sobre o trabalho presente em sua dissertação de mestrado, realizada no Instituto de Artes da UFRGS. O objeto, corpo do poema em 
forma de sabonete, seria capaz de gerar certa perturbação, desafiando a palavra poética. $O$ sabonete, deslocado de seu contexto utilitário, mas também funcionando como produto, poderia pressionar a metáfora.

Um sabonete de nome Pôncio Pilatos, cujo slogan é "O inconfundível cheirinho de culpa", de fato provoca as referências nele contidas. Afinal, o perfume que o caracteriza gera uma descontinuidade em relação à função de um sabonete. Quando Pôncio Pilatos lava suas mãos, na famosa passagem dos evangelhos, é para livrar-se daquilo que configura o próprio distintivo do produto, esse odor "inconfundível". Essa é a tensão central inicial determinante dos deslocamentos operados na imagem poética expandida que constitui o poema de Dourado.

O trabalho se configura, em um primeiro nível, como poema-produto, um sabonete de base vegetal de $90 \mathrm{~g}$, muito semelhante aos outros disponíveis no mercado, e teve um lote inicial de 100 unidades, as quais foram comercializadas em São Luiz e em Porto Alegre. Não apenas as características do sabonete apontam para as inflexões que seu caráter de produto gera sobre a metáfora, mas também a presença do vídeo, dirigido por Emílio Sagaz Andrade e disponível no Youtube. ${ }^{5}$

No vídeo publicitário, há uma trilha original, de autoria de Emílio Sagaz, com o refrão "Nada de culpa, nada de culpa / Sabonete é Pôncio Pilatos" e versos como: "Você mais leve / Pra você que deve / Limpa seu juízo com espuma cremosa". Um apresentador de terno e gravata, que salienta os benefícios da mercadoria, diz que a qualidade é atestada "desde os tempos de Nosso Senhor Jesus Cristo". Ele segue: "A voz do povo é a voz de Deus, vamos ver o que o pessoal está achando aí na rua do nosso sabonete". Então quatro atores, representando populares, nas ruas, chamam a atenção para as qualidades do sabonete: "É cheiroso", "É divino", "É maravilhoso", "Com ele, eu lavo as minhas mãos".

O tom humorístico prepondera no vídeo, no qual a utilização de elementos que parodiam os comerciais que atingem setores massivos da população (sem sofisticação em termos estéticos e de elaboração formal) gera efeito altamente cômico, que ressalta as qualidades da metáfora estruturante do trabalho de Dourado. O aspecto "tosco" do comercial repete alguns elementos conhecidos do grande público nas propagandas às quais estamos expostos cotidianamente: "Você se sente culpado? Não se sinta mais. Nós temos a solução para os seus problemas", diz o apresentador do comercial. Trabalha-se aqui com a exploração dos clichês. O vídeo acentua o sabor do trocadilho com a frase final: "Em breve, xampu Barrabás, para os seus cabelos ficarem bem soltinhos" é a última fala do vídeo, dita pelo próprio Diego Dourado, empunhando o tabuleiro cheio de sabonetes coloridos, em meio aos passantes da rua movimentada.

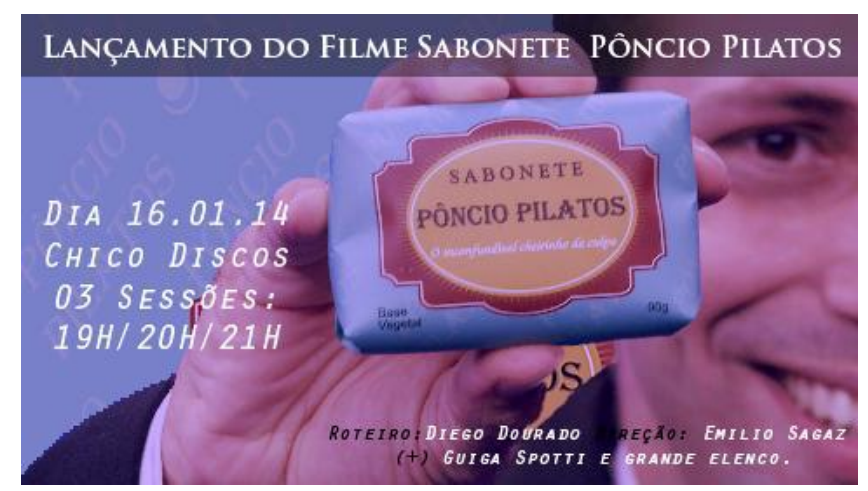

Figura 3 - Diego Dourado, Sabonete Pôncio Pilatos, 2014. Webflyer de divulgação do vídeo publicitário.

Fonte: Dourado (2016, p. 138).

\footnotetext{
${ }^{5}$ Disponível em: https://www.youtube.com/watch?v=C_HYElIzEGo. Acesso em: 2 fev. 2019.
} 
O vídeo constitui um trabalho em separado, que se alicerça sobre o poema-objeto, dele derivando. Há uma forte dependência do trabalho em vídeo em relação ao trabalho de Dourado. O poema, enquanto objeto e enquanto performance, no entanto, prescinde do comercial, mas é por ele completado no sentido de um reforço de certas características, enquanto jogo que leva ao lúdico. Mais que um nível diferente do trabalho, o vídeo parece ser uma espécie de intertexto derivativo do poema.

As parcerias geram novas configurações, tanto quanto a utilização de uma mídia que inclui espaço e tempo entre suas características centrais. As imagens em movimento, que Helder citou como derivativas do quadro, com todos os elementos que a linguagem comporta, são muito mais abrangentes no sentido da percepção, proporcionando sinestesias, imersão, sequência temporal. Ao definir as características centrais da linguagem cinematográfica, o próprio Eisenstein recorreu à leitura de outras artes. $\mathrm{O}$ conflito entre as imagens, que é gerado na edição, segundo ele, seria a característica mais marcante da própria linguagem da montagem de imagens em movimento (Eisenstein, 1958).

Além de imagens em movimento, o vídeo tem outras implicações, visto que cria uma relação com a publicidade, a qual mimetiza, gerando humor por meio de suas determinações intertextuais, liberadoras de efeitos lúdicos. Com efeito, o vídeo dialoga com os comerciais préexistentes tanto quanto Sabonete Pôncio Pilatos dialoga com produtos como Phebo ou Granado. Nenhum desses trabalhos está isolado da rede de relações com os trabalhos que os precederam, criando diálogos constantes, reativando camadas de significado e colocando em movimento um conjunto de referências (Fiorin, 2003).

O jogo brincante da metáfora inicial, espacializada no sabonete, estabelece-se como elemento central do vídeo, sendo ampliado pelas possibilidades matéricas mais abrangentes que esse possibilita: sequência e montagem, copresença de sons e imagens, atores, efeitos da edição, como os que seguem: sabonetes trocam de cor no fundo da imagem, piscando; os quatro transeuntes aparecem ao mesmo tempo, no plano dividido, dizendo ao mesmo tempo o texto "Com ele eu lavo as minhas mãos" etc. A linguagem do cinema, caracterizada pelo recorte, pelo conflito entre os fragmentos que se sucedem, vem redimensionar a imagem poética central, levando-a a habitar outros campos, que incluem uma espacialização muito mais radical.

A ação de vender os sabonetes na rua, diferente do comercial, pode estar mais próxima do núcleo mesmo do trabalho - o qual, em um primeiro nível, é constituído pelo sabonete em si. O mero contato com o objeto, a leitura de seu nome e slogan, se não esgotam as possibilidades do trabalho, são suficientes para o acesso às inflexões das escolhas materiais, para o modo como o poema se constitui enquanto possibilidade de "espacialização da palavra". A discussão pode ser colocada nos seguintes termos: em que medida o trabalho de Diego Dourado encarna essa espacialização, ou seja, como as possibilidades da poesia expandida oportunizam um modo de acontecer do poema que não seria possível em outros meios e materialidades, e quais as consequências dessas escolhas ampliadas? Parece que a espacialização obtida oportuniza, muito mais do que um conjunto de determinações formais/linguísticas, um conjunto de vivências, uma atuação social do poema. As escolhas, em termos de materialidades, de modos de acontecer do poema como presença física, estão relacionadas com uma apreensão política da construção do texto. A espacialização da palavra pretendida não seria apenas uma experimentação linguística, mas, sim, o sintoma de um posicionamento político autoconsciente de suas necessidades e das reverberações de suas escolhas.

O trabalho de Diego Dourado pode ser relacionado com as inserções em circuitos ideológicos de Cildo Meireles, a fim de tornar presente para a discussão o modo como ele agencia escolhas matéricas, modo de circulação e contexto social. Nesse conjunto de trabalhos, realizados durante o período da ditadura militar no Brasil, o artista intervém em objetos de circulação - dois trabalhos muito famosos são seus carimbos em notas de dinheiro, que passam de mão em mão, e suas serigrafias em garrafas retornáveis de Coca-Cola. Nesses trabalhos, há um caráter subversivo: nas garrafas, são inscritas receitas de coquetel molotov, por exemplo; nas notas de dinheiro, é carimbada a pergunta "Quem matou Herzog?". Opera-se um desvio do lugar do artista-autor como quem assina o trabalho, que tem de ficar incógnito para a eficácia 
da própria obra e em virtude do contexto e seus perigos constantes. Marjorie Perloff (2013), em O gênio não original: poesia por outros meios no novo século, investiga os procedimentos através dos quais os poetas passam a produzir obras nas quais está presente essa característica. A negação da originalidade se manifesta em obras que pontuam o apagamento do autor.

O poema-objeto de Diego Dourado, quando vendido nas ruas, ao mesmo tempo que expõe o trabalho a um fluxo maior de pessoas, também apaga a autoria e sua existência enquanto objeto de arte. Intervém no cotidiano com potencial de gerar questionamentos sobre um conjunto de problemas atuais envolvendo a religiosidade, a moral cristã, a cultura de higienização, a desatenção/falta de presença a que somos expostos na vida cotidiana das grandes cidades, a redução das pessoas a consumidores, entre uma série de outras questões que podem ser levantadas. Enquanto objeto de circulação, o sabonete esconde e revela sua potencialidade, fazendo lembrar das garrafas de Coca-Cola, nas quais está aparente e escondido o texto serigrafado.

A ironia presente no slogan do trabalho de Diego, ao mesmo tempo que provoca o riso, também levanta questionamentos sobre os lugares comuns envolvendo a religiosidade e a presença da moral cristã no cotidiano das grandes cidades. Ele enfrenta o sagrado da passagem bíblica, lançando sobre ela uma provocação. Há uma afronta da fé cega, que também deve ser considerada como gesto político e atuação do trabalho no campo social. Há um enfrentamento dos discursos hegemônicos acerca das noções de culpa e suas relações com a moral cristã. Esse gesto não é desprovido de radicalidade: no século XX, José Saramago sofreu perseguição por afrontar a narrativa religiosa hegemônica com seu romance $O$ evangelho segundo Jesus Cristo, entre tantos outros exemplos. No contexto atual, com o crescimento do fundamentalismo na cultura brasileira e sua inserção midiática e política, o trabalho de Dourado pontua uma afronta, colocando-se, de modo bem humorado e quase silencioso, contra a ordem vigente, nisso aproximando-se (salvaguardadas as diferenças de contexto e conteúdo simbólico) do trabalho de Cildo Meireles.

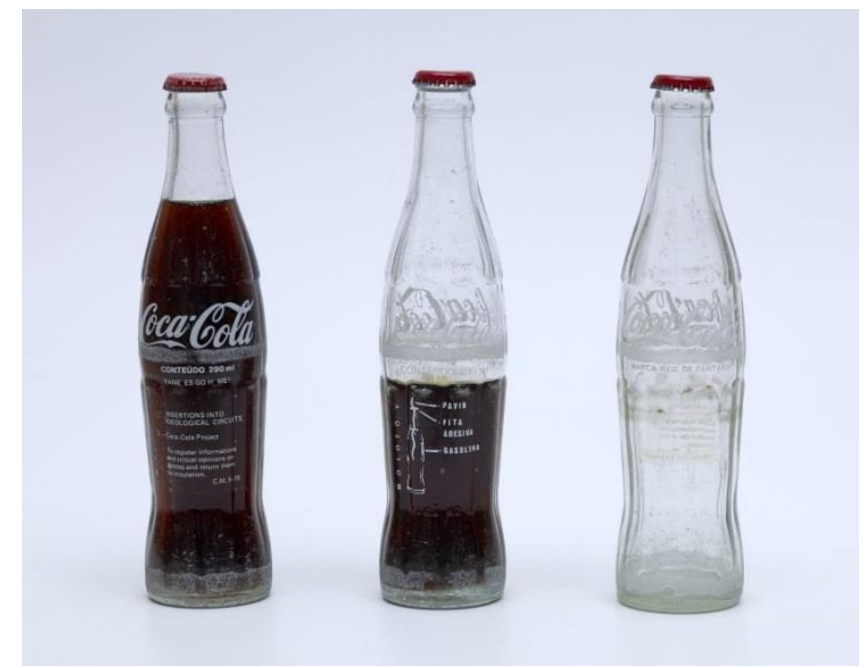

Figura 4 - Cildo Meireles, inserções em circuitos ideológicos: Projeto Coca-cola, 1970, serigrafia sobre garrafa retornável.

Fonte: Museu Reina Sofia. ${ }^{6}$

É fato que o poeta, a partir de uma formação em artes visuais, está consciente das implicações do agenciamento das materialidades, utilizando-as a favor da composição - inclusos aí os modos de circulação do trabalho, a partir de uma consideração das mídias envolvidas e dos procedimentos ampliados. Para compreender o trabalho, é possível lançar mão do conceito de campo expandido, proposto por Rosalind Krauss (2004). Criado para entender fenômenos da escultura dos anos 1960 e 1970 e emprestada para a poesia contemporânea, essa ferramenta teórica fornece sugestões que

${ }^{6}$ Disponível em: https://bit.ly/31TU5Ma. Acesso em: 22 fev. 2019. 
podem ser frutíferas, no sentido de incorporar elementos não apenas restritos à produção/recepção, mas aos lapsos e relações com a paisagem e a não paisagem que emergem como possibilidades de relação diante do trabalho poético.

A escultura, quando se liberta do suporte e dos meios e modos de manifestação tradicionais, anteriores à geração minimalista-conceitual, passa a existir em um campo no qual dialogam elementos e relações mais abrangentes, propondo questionamentos sobre espaço, arquitetura e paisagem. $\mathrm{O}$ aparato crítico para compreendê-la torna-se insuficiente. Krauss considera a relação da escultura com a lógica do monumento, que passa a ser enfraquecida a partir de obras como as de Rodin e Brancusi, que recusam o pedestal e ampliam as possibilidades da linguagem tridimensional. A partir desse jogo, a escultura passa a exercer-se contra o próprio conceito, recusando a lógica do monumento e, até mesmo, da escultura, sendo impossível abarcar todas as possibilidades utilizadas a fim de torná-la, tanto quanto possível, distante da circunscrição do conceito tradicional.

Krauss recorre, então, a um estratagema lógico, a uma regularização em diagrama dessas relações, a fim de mostrar que estas não estão limitadas aos padrões presentes no conceito tradicional. A partir do movimento criativo realizado pelos artistas, alargou-se de maneira tão radical o conceito, que se tornou necessário interpretá-lo através das relações que se estabelecem entre escultura, paisagem, não paisagem, arquitetura e não arquitetura. Em vez de uma única definição, a escultura passa a se mostrar, então, em uma rede de relações e interações. De modo análogo, quando consideramos o modo como o trabalho de Dourado levanta questões acerca do conceito de poesia, percebemos que ele pratica expansões e um jogo complexo de interações.

Os elementos que seriam tradicionalmente pensados como não verbais desempenham um papel fulcral na constituição do trabalho. Não é possível compreender o Sabonete Pôncio Pilatos sem o acesso ao entorno no qual ele habita, às relações com seu caráter de produto, com a propaganda, com a compra e venda. É um poema que extrapola a materialidade das palavras, forçando o entendimento de que a poesia seria arte verbal. Pensarmos um poema em forma de sabonete vendido nas ruas e não em forma de palavras (sejam elas impressas ou cantadas) pode ser tão estranho quanto, diante de uma escultura que segue a lógica do monumento, pensar que um círculo no chão, formado por passos de uma caminhada repetida, é uma escultura. A expansão do campo, no qual a ampliação das possibilidades construtivas é a tônica dos procedimentos adotados, é um aspecto comum, tornando possível o entendimento do poema a partir do conceito de Rosalind Krauss.

Há uma característica de agenciamento do plano expandido que também é comum ao Sabonete Pôncio Pilatos e a muitas das obras que provocaram as reflexões de Rosalind Krauss. Se uma escultura, ao ser construída com espelhos, como ocorre com os trabalhos de Richard Morris e Robert Long, passa a absorver seu entorno dentro da própria essência da sua construção e a paisagem passa a fazer parte do trabalho, também as determinações do produto sabonete, sua base vegetal, seu caráter de mercadoria que circula no meio de compra e venda em camelôs, faz parte das próprias características da proposição enquanto poema.

O trabalho de Dourado não é apenas, então, um poema-objeto, mas absorve os aspectos do contexto e do entorno: o trabalho informal, a velocidade com que as pessoas passam pelas ruas, a existência de produtos que copiam as marcas mais apreciadas e são vendidos abaixo do preço, ou seja, uma série de implicações do entorno social, do contexto, que entranham o trabalho, enquanto Sabonete Pôncio Pilatos.

É possível concluir que o mecanismo de ampliação/expansão utilizado na construção do nosso objeto de leitura gera implicações não apenas no sentido de exploração formal e construtiva, ou da constituição do texto enquanto matéria, mas são o reflexo de um contexto de criação e recepção de poesia que se coaduna com o momento social e político. Os escultores que propuseram as expansões compreendidas por Krauss posicionaram-se, ao alargarem o campo, contra um contexto no qual a arte era vista como objeto e também, na medida em que se opõem à lógica do monumento, às relações com o poder institucional. O poema de Dourado, ao agenciar as expansões que ele materializa, configura-se como uma forte crítica ao caráter elitista 
da poesia livresca, colocando-se ao lado da circulação nas ruas, dialogando com o trabalhador comum que compra um sabonete no camelô.

As possibilidades da poesia expandida têm criado modos de responder ao contexto institucional da poesia e também às questões da cultura. Ao forçar a linguagem, expandindo as possibilidades da metáfora, gerando novas espacializações, o poema-sabonete se concretiza como ação direta, como ponto de convergência de uma postura crítica em relação às religiões, mas também de uma reação à própria consciência do papel social do poema.

\section{Referências}

ALEIXO, Ricardo (2017). Encontros: a arte da entrevista. Rio de Janeiro: Beco do Azougue.

AUSLANDER, Phillip (2012). A performatividade da documentação de performance. Tradução Jorge Menna Barreto. ¿Hay em Portugués?, Florianópolis, n. 2, s.p.

CAMPOS, Augusto de; PIGNATARI, Decio; CAMPOS, Haroldo de (2006). Teoria da poesia concreta: textos críticos e manifestos 1950-1960. São Paulo: Ateliê.

DA VINCI, Leonardo (1943). Tratado de la pintura. Tradução Mario Pittaluga. Buenos Aires: Losada.

DOURADO, Diego (2014). Exclusivo - Entrevista com o Poeta e Artista Plástico Diego Dourado. [Entrevista cedida a] Anand Rao. Cultura Alternativa, 9 nov 2014. 10min29s. Disponível em: https://bit.ly/324bsSx. Acesso em: 2 fev. 2019.

DOURADO, Diego (2015). Antologia dos estilhaços. Rio de Janeiro: 7Letras.

DOURADO, Diego (2016). Convergência: relações entre arte, poesia e música. Dissertação (Mestrado em Artes Visuais) - Universidade Federal do Rio Grande do Sul, Porto Alegre.

FRIAS, Joana Matos (2008). Ut pictura poesis non erit. Lisboa: Revista Relâmpago, v. 10, n. 23, p.163-179.

FIORIN, José Luiz et al. (2003). Dialogismo, polifonia, intertextualidade. São Paulo, Edusp.

EISENSTEIN, Sergei (1958). Film form and The film sense: two complete and unabridged works by Sergei Eisenstein. Tradução de Jay Leyda. New York: Meridian Books.

HELDER, Herberto (2017). Photomaton E vox. Rio de Janeiro: Tinta-da-china Brasil.

KRAUSS, Rosalind (2004). A escultura no campo ampliado. Arte E Ensaios, Rio de Janeiro, 17, p.128-137.

LESSING, Gotthold Ephraim (2011). Laocoonte ou sobre as fronteiras da Pintura e da Poesia. Tradução Márcio Seligmann-Silva. São Paulo: Iluminuras.

LICHTENSTEIN, Jacqueline (Org) (2006). A pintura: textos essenciais. São Paulo: Ed. 34. v. 5.

MARTELO, Rosa Maria (2012). O cinema da poesia. Lisboa: Documenta.

PERLOFF, Marjorie (2013). O gênio não original: poesia por outros meios no novo século. Belo Horizonte: Editora UFMG.

POUND, Ezra (s.d.). ABC da literatura. Tradução de Augusto de Campos e José Paulo Paes. São Paulo: Cultrix.

SABONETE Pôncio Pilatos. Roteiro de Diego Dourado. Direção de Emílio Sagaz Andrade. Produzido por Orige e sagazrock, com trilha original e edição de Emílio Sagaz. 2 min 41 seg. Disponível em: https://www.youtube.com/watch?v=C_HYElIzEGo. Acesso em: 2 fev. 2019. 